Gut, 1980, 21, 970-976

\title{
Observations on copper associated protein in childhood liver disease
}

\author{
J EVANS,* S P NEWMAN, AND S SHERLOCK \\ From the Departments of Medicine and Medical Physics, Royal Free Hospital, London
}

SUMMARY Hepatic copper concentrations were compared with staining grades of copper associated protein (CAP) and histochemical copper in liver sections from 44 patients (one fetus, one pre-term infant, four term infants, eight normal children, 16 children with various liver diseases, and 14 patients with intrahepatic cholestasis of childhood (IHCC)). A similar comparative study of hepatic copper concentration with CAP and histochemical copper was performed in 21 patients with Wilson's disease. CAP occurred in the fetus, pre-term infant, and term infants without liver disease. This suggests that CAP is a normal constituent of the hepatocyte and is not a consequence of liver disease or biliary obstruction. CAP was not seen when hepatic copper concentration was normal; it was absent in eight children with no evidence of liver disease, eight children with non-cirrhotic liver disease, and seven of eight children with cirrhosis. When hepatic copper concentration exceeded $4.0 \mu \mathrm{mol} / \mathrm{g}$ dry liver weight grade 2 or grade 3 staining for CAP and histochemical copper was found in the fetus, pre-term infant, infants, and IHCC. CAP was found in IHCC only in the presence of raised hepatic copper levels, supporting evidence of a relationship between copper and CAP. In 17 of 21 patients with Wilson's disease hepatic copper concentrations exceeded $4 \mu \mathrm{mol} / \mathrm{g}$. Positive staining for CAP was seen in seven of these patients being usually grade 1. CAP is a normal associated protein, present when hepatic copper concentrations are increased in normal liver cells. It is usually absent in hepatocytes from Wilson's disease despite similar hepatic copper levels. CAP may represent material which protects the hepatocyte from the toxic effects of copper.

Sipponen et al. ${ }^{1}$ noted a new material in liver sections from patients when stained with the orcein stain of Shikata. ${ }^{2}$ This material was present in $83 \%$ of patients with primary biliary cirrhosis (PBC), $20 \%$ of patients with active chronic hepatitis, and a few patients with long-standing cirrhosis. It appeared as dark brown granules distinguishable from $\mathrm{HBsAg}$ and elastic tissue by staining pattern and location, and occurred in the same cellular and subcellular location as copper. Other materials such as lipofuscin and globules of $\alpha$ l-antitrypsin are not stained by orcein. ${ }^{3}$ The protein nature of this new material was suggested by histochemical stains and it was named copper associated protein (CAP). ${ }^{3}$ CAP has been considered an abnormal copper binding protein. ${ }^{4}$

Measured copper concentration in liver sections from patients with PBC has been shown to correlate with grades of staining of CAP and histochemical

*Address for reprint requests: Dr J Evans, Department of Gastroenterology, Princess Alexandra Hospital, Ipswich Road, Brisbane, Queensland, Australia.

Received for publication 19 June 1980 copper. ${ }^{5}$ However, this relationship has not previously been systematically studied and reported in children. Hepatic copper concentration is physiologically raised in fetuses and newborn infants ${ }^{6}$ and remains raised until 6 to 12 months of age.? Hence, liver sections from a neonatal group have been examined for CAP and histochemical copper in the present study.

In Wilson's disease, copper accumulation in the liver (usually $>4 \mu \mathrm{mol} / \mathrm{g}$ of dry liver) and other organs is associated with tissue damage. ${ }^{8}$ The relationship between the measured hepatic copper concentration and grades of staining for CAP, and histochemical copper was assessed in patients with Wilson's disease and the findings compared with other groups.

\section{Methods}

STUDY GROUPS

Sixty-five liver sections were assessed from (1) neonatal group (six) (2) childhood group (38), and (3) Wilson's disease (21). 


\section{Neonatal group}

All six patients died from non-hepatic causes and included one fetus of 27 weeks' gestation, the result of an antepartum haemorrhage, and one pre-term infant of 35 weeks' gestation with congenital heart disease (CHD) who died on the third post-partum day from heart failure. The four term infants included one child with Down's syndrome who died on the first day post-partum from a tear in the falx cerebri, one infant with a tracheo-oesophageal fistula who died from respiratory failure at 3 weeks of age, and two infants with CHD who died from heart failure at 7 days and 2 months respectively. Wedge samples were obtained at necropsy in all cases.

\section{Childhood group}

The 38 children were at least 18 months old, and each group was age-matched. No child had received copper chelation therapy.

Eight children were ultimately proved to have no evidence of liver disease. Percutaneous liver biopsies were obtained in six and wedge samples were obtained at necropsy in two.

Fourteen children suffered with intrahepatic cholestasis of childhood (IHCC). Of the 14 patients in this group, 13 developed jaundice in the first 3 months of life and one presented with pruritis at 3 years of age. Their ages at the time of study ranged from 18 months to 22 years. Liver specimens were obtained by percutaneous biopsy in 13 and at necropsy in one. Diagnosis was based on clinical, biochemical, and biopsy evidence. ${ }^{9}$ Extrahepatic biliary obstruction was excluded in all cases: in nine by laparotomy and in five by percutaneous transhepatic cholangiography and ultrasound examination. A family history of liver disease was obtained only in one case-a brother with IHCC had died after haemorrhage from oesophageal varices. Pulmonary flow murmurs were present in two children and one child also had congenital glaucoma. In these two children there was no evidence of pulmonary valves stenosis as assessed clinically, with ECG, radiograph of the chest, or echocardiography. Arteriography was not performed. All cases were negative for hepatitis $\mathbf{B}$ surface antigen and surface antibody and hepatitis $\mathbf{B}$ core antibody. One patient, homozygous for $\alpha 1$-antitrypsin deficiency, had cholestasis from the neonatal period. Children with characteristic facies and cardiac lesions, ${ }^{10}$ Byler's syndrome, ${ }^{11}$ or arteriohepatic dysplasia $^{12}$ were not present in this series. The patients were of various nationalities: six English, three Italians, three Arabs, two Greeks, and one Portuguese. None had had portal systemic shunt surgery.

Eight children suffered from cirrhosis-no cause was identified in five. The test for $\mathrm{HBsAg}$ was positive in one child; one child was homozygous for $\alpha 1$-antitrypsin deficiency; one child had fatty cirrhosis, possibly due to type III glycogen storage disorder.

Eight children suffered from various liver diseases excluding cirrhosis, biliary cirrhosis, and Wilson's disease.

\section{Wilson's disease}

Among the 21 patients in this group there were four sibling pairs (nos. 1,$5 ; 6,10 ; 8,17 ; 13,21$ ). The diagnostic pre-penicillamine biopsy was studied in 11.

\section{Techniques}

Tissue copper concentration was determined by neutron activation analysis. The instruments used for taking liver samples were washed with $1 \%$ solution of ethylenediaminetetraacetic acid (EDTA), rinsed with ion-free water, and sterilised in a similarly prepared glass container. Copper contamination of necropsy wedge samples was specifically avoided. Hepatic copper concentration was expressed as $\mu \mathrm{mol} / \mathrm{g}$ dry liver weight. The coefficient of variation for duplicate measurements of hepatic copper concentration measured by neutron activation analysis is $7 \%$ to $15 \%$.

A portion of each liver sample was used for estimation of copper by neutron activation analysis (NAA). The remainder was processed for paraffin sectioning and stained for copper associated protein and tissue copper by the methods of Shikata et al. ${ }^{2}$ and Lindquist ${ }^{13}$ respectively. If positive staining occurred, the degree was semi-quantitatively assessed at grade 1, 2, or 3 for mild, moderate, or heavy staining. Absent staining was grade 0 .

Histological semi-quantitative grading was performed without prior knowledge of liver copper concentration.

The Mann-Whitney test was used for statistical analysis of hepatic copper levels in the six groups of patients.

\section{Results}

\section{CHILDHOOD CONTROLS}

In eight histologically normal liver biopsies the hepatic copper concentration was $0.5 \quad(0.2-1 \cdot 5)$ $\mu \mathrm{mol} / \mathrm{g}$ dry liver (median and range). This value is similar to figures quoted for normal adults. ${ }^{14}{ }^{15}$ Liver sections did not stain positively with orcein or rhodanine.

\section{NEONATAL GROUP}

Hepatic copper concentration was significantly increased in six, being $5 \cdot 5(2 \cdot 2-10 \cdot 7) \mu \mathrm{mol} / \mathrm{g}$ 


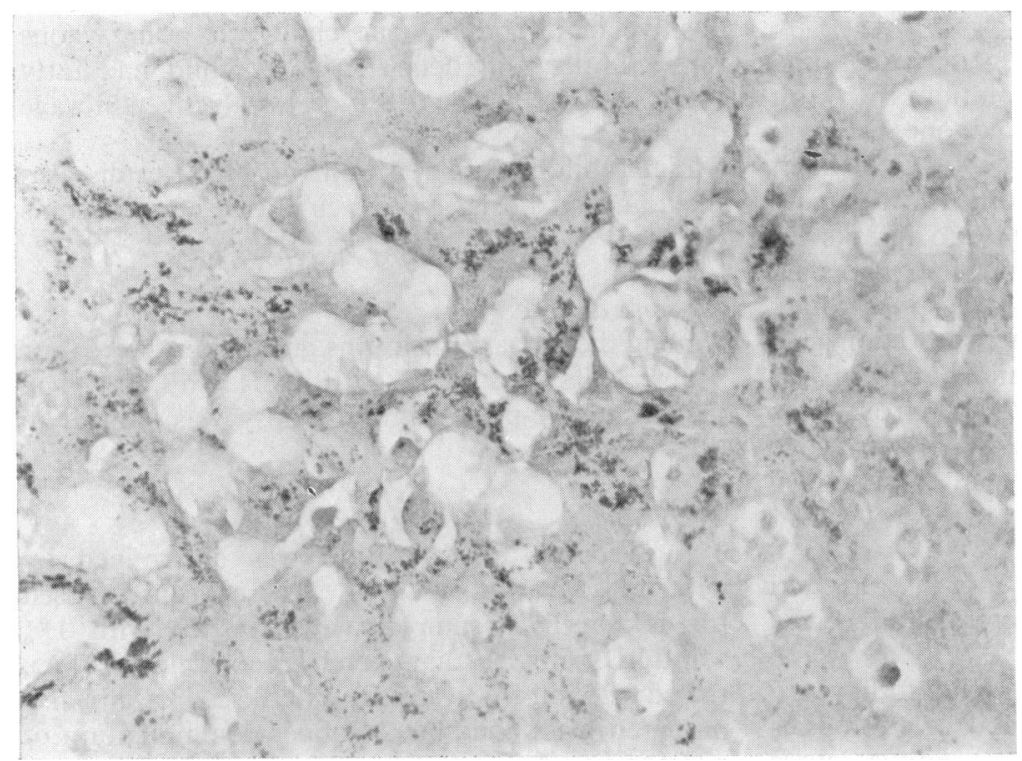

Fig. 1 Copper associated protein. Typical granules of CAP observed sith orcein staining in liver sections from pre-term infants of 35 weeks' gestation. Hepatic copper concentration was $6.9 \mu \mathrm{mol} / \mathrm{g} \times$ 300.

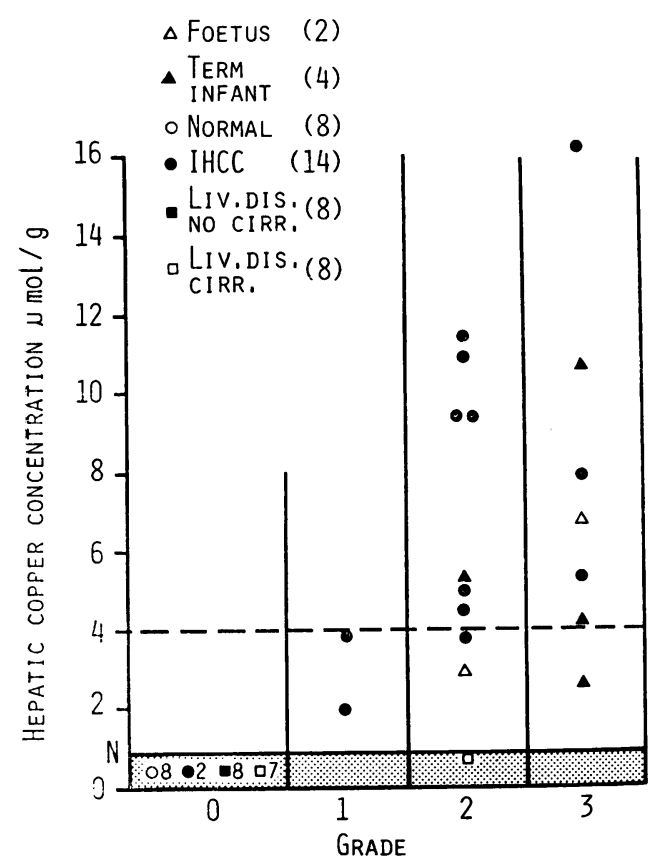

Fig. 2 Neonatal and childhood groups, excluding Wilson's disease: grades of copper associated protein (orcein) staining and hepatic copper concentration. Each group is represented by a different symbol. The hatched area represents normal hepatic copper concentration. A liver copper concentration exceeding $4 \mu \mathrm{mol} / \mathrm{g}$ is considered to be one of the diagnostic features of Wilson's disease.
$(\mathrm{P}<0.001)$. Liver histology revealed no evidence of acute or chronic liver disease. Positive staining with orcein and rhodanine was seen in the fetus, pre-term infant, and the four term infants (Fig. 1). CAP seen in these cases appeared to be identical with that described in adults. ${ }^{1}$

\section{INTRAHEPATIC CHOLESTASIS OF CHILDHOOD (I HCC)}

Hepatic copper concentration was significantly increased in 12 of 14 children being $5 \cdot 1(0 \cdot 9-16 \cdot 2)$ $\mu \mathrm{mol} / \mathrm{g}(\mathrm{P}<0.001)$. Typical orcein positive granules of CAP were seen in the 12 with raised hepatic copper levels (Fig. 2). Positive staining with rhodanine occurred in 11 of 12 patients with raised hepatic copper levels. Liver sections from one patient with slightly increased hepatic copper concentration did not stain with rhodanine and sections from one patient with normal hepatic copper concentration showed grade 1 staining (Fig. 3).

\section{LIVER DISEASE}

Liver copper levels in eight children with noncirrhotic liver disease and eight children with cirrhosis were $0.4(0.2-1 \cdot 2) \mu \mathrm{mol} / \mathrm{g}$ and $0.7(0.3-1 \cdot 1)$ $\mu \mathrm{mol} / \mathrm{g}$ respectively. These values are in the normal range. Liver sections did not stain positively with orcein or rhodanine in children with non-cirrhotic liver disease.

Sections from one patient with cirrhosis (homozygous $\alpha 1$-antitrypsin deficiency) revealed grade 2 orcein staining with normal hepatic copper concen- 


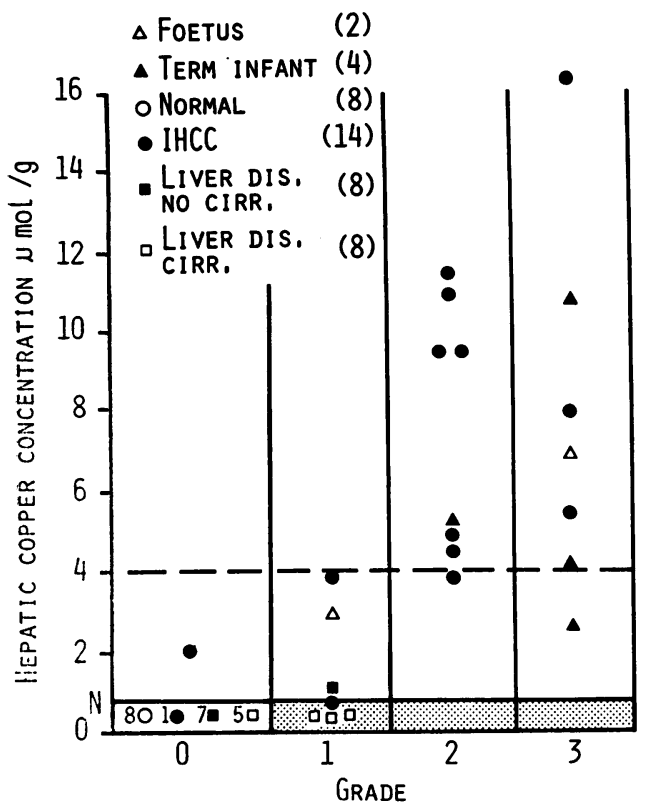

Fig. 3 Neonatal and childhood groups, excluding Wilson's disease: grades of histochemical copper (rhodanine) staining and hepatic copper concentration. Each group is represented by a different symbol. The hatched area represents normal hepatic copper concentration. A liver copper concentration exceeding $4 \mu \mathrm{mol} / \mathrm{g}$ is considered to be one of the diagnostic features of Wilson's disease.

tration (Fig. 2). Grade 1 rhodanine staining was present in sections from this patient and two others with normal hepatic copper levels (Fig. 3).

\section{WILSON'S DISEASE}

Positive staining patterns of CAP in Wilson's disease differed qualitatively and semi-quantitatively from the preceding groups (Table). If CAP staining occurred, it was distributed irregularly throughout the hepatic parenchyma.

Hepatic copper concentration was significantly increased being $8.69(1.91-28.94) \mu \mathrm{mol} / \mathrm{g}(\mathrm{P}<0.001)$ and in 17 patients exceeded $4 \mu \mathrm{mol} / \mathrm{g}$. However, CAP was seen in only seven patients. Grade 1 staining was most common, being present in four patients, and grade 3 staining occurred in one patient (hepatic copper concentration $8.69 \mu \mathrm{mol} / \mathrm{g}$ ).

In two patients CAP was absent when liver sections appeared normal and hepatic copper levels were high (nos. 11, 12). CAP was frequently associated with cirrhosis, being present in seven of 11 patients with cirrhosis. Hepatic copper concentrations in the group with cirrhosis was 6.94 (1.9122.52) $\mu \mathrm{mol} / \mathrm{g}$, which was not significantly different from cases without cirrhosis 9.22 (2.63-28.94)
Table Grades of staining of histochemical copper (rhodanine) and copper associated protein (orcein), hepatic copper concentration, histological assessment, and treatment in 21 patients with Wilson's disease.

\begin{tabular}{|c|c|c|c|c|c|}
\hline No. & $\begin{array}{l}\text { Liver copper } \\
\text { concentration } \\
(\mu \mathrm{mol} / \mathrm{g})\end{array}$ & $\begin{array}{l}\text { Histochemical } \\
\text { copper grade }\end{array}$ & $\begin{array}{l}\text { Copper } \\
\text { associated } \\
\text { protein } \\
\text { grade }\end{array}$ & Histology & $\begin{array}{l}\text { Treatment } \\
(y r)\end{array}$ \\
\hline 1 & 1.91 & 1 & 2 & C & - \\
\hline 2 & 4.69 & 0 & 1 & C & - \\
\hline 3 & $6 \cdot 14$ & 3 & 2 & $\mathbf{C}$ & - \\
\hline 4 & 6.94 & 0 & 0 & Infl C & - \\
\hline 5 & 8.69 & 3 & 3 & C & - \\
\hline 6 & $11 \cdot 15$ & 0 & 0 & Fat Infl Fib & - \\
\hline 7 & 12.06 & 1 & 1 & C & - \\
\hline 8 & 15.84 & 1 & 0 & $\begin{array}{l}\text { Fat Infl Fib } \\
\text { ?C }\end{array}$ & - \\
\hline 9 & $20 \cdot 38$ & 0 & 0 & Fat Infl C & - \\
\hline 10 & 22.52 & 1 & 0 & Infl C & - \\
\hline 11 & 28.94 & 0 & 0 & $\mathbf{N}$ & - \\
\hline 12 & 2.63 & 0 & 0 & $\mathbf{N}$ & 10 \\
\hline 13 & 3.01 & 1 & 1 & C & 8 \\
\hline 14 & $3 \cdot 13$ & 0 & 0 & C & 15 \\
\hline 15 & $5 \cdot 29$ & 0 & 0 & Fat Infl Fib & 3 \\
\hline 16 & 5.57 & 0 & 0 & $\mathbf{A C H}$ & 16 \\
\hline 17 & $5 \cdot 73$ & 1 & 0 & $\mathrm{ACH}$ & 1 \\
\hline 18 & 8.74 & 0 & 0 & Fib & 14 \\
\hline 19 & $9 \cdot 70$ & 0 & 0 & Fat fib & 9 \\
\hline 20 & 12.47 & 1 & 0 & Fat & 4 \\
\hline 21 & 15.43 & 1 & 1 & Fat $\mathrm{C}$ & 6 \\
\hline
\end{tabular}

Histological assessment: $\mathrm{N}$ : normal. Infl: inflammation. Fib: fibrosis. C: cirrhosis. ACH: active chronic hepatitis.

$\mu \mathrm{mol} / \mathrm{g}$. CAP appeared more common in the pretreatment group. The hepatic copper concentration in the pre-penicillamine group was 11.15 (1.9128.94) $\mu \mathrm{mol} / \mathrm{g}$, which was not significantly different from patients with treated Wilson's disease 5.65 $(2 \cdot 63-15 \cdot 43) \mu \mathrm{mol} / \mathrm{g}$ or patients with IHCC $5 \cdot 1$ $(0 \cdot 9-16 \cdot 2) \mu \mathrm{mol} / \mathrm{g}$.

Four sibships were studied. Similar staining patterns for CAP were seen in siblings in all families despite large differences of hepatic copper levels and variable histological appearances. Thus CAP was not seen in both siblings from two families (nos. 6, 10 and 8,17 ), grade 1 CAP staining occurred in both siblings from one family (nos. 13, 21) and moderate staining was detected in both siblings (nos. 1, 5) of the fourth family.

There was no correlation between grade of histochemical staining for copper and hepatic copper concentration measured by neutron activation analysis. Ten of the 21 patients had positive staining for copper, being usually grade 1 . Grade 3 staining for copper occurred in only two patients and hepatic copper concentrations were $6.14 \mu \mathrm{mol} / \mathrm{g}$ and 8.69 $\mu \mathrm{mol} / \mathrm{g}$.

\section{Discussion}

Measurement of liver copper concentration is not widely available. ${ }^{15}$ Histochemical assessment 
of hepatic copper concentration, if reliable, would provide clinically useful information more readily. The orcein stain of Shikata and rhodanine stains appear to demonstrate different components of a copper-protein complex in liver sections. ${ }^{45}$ Similar staining grades for copper and copper associated protein (CAP) were usually observed in each liver section in the study of neonatal and childhood groups. When hepatic copper levels were normal positive staining for copper and CAP was usually absent. However, staining for CAP appeared more discriminatory, being positive in one instance only when hepatic copper concentrations were normal. This patient suffered from cirrhosis with homozygous $\alpha 1$-antitrypsin deficiency. $\alpha 1$-antitrypsin globules are not detected by the orcein stain $^{3}$ and the discrepancy may be related to different sections of the biopsy being assessed histologically and by neutron activation analysis. There was a relationship between measured hepatic copper concentrations and grades of staining for tissue copper and CAP. Usually, slight rises of hepatic copper concentration $(<4 \mu \mathrm{mol} / \mathrm{g})$ were associated with grade 1 staining and large increases of hepatic copper levels $(>4$ $\mu \mathrm{mol} / \mathrm{g}$ ) were associated with grade 2 or grade 3 staining. A wide range of hepatic copper concentrations occurred with grade 2 or grade 3 staining, thus limiting useful interpretation of grades of histological staining in individual patients.

All patients in the neonatal group were less than 3 months of age. The hepatic copper concentrations were physiologically increased ${ }^{6}$ and liver sections appeared normal. The study of this group revealed typical granules of CAP in all cases, suggesting that it is also physiological and represents a normal hepatocyte protein rather than an abnormal tissue copper protein (metallothionein) as previously suggested. ${ }^{4}$ CAP has been described in primary biliary cirrhosis and chronic liver disease. ${ }^{1}$ Histologically, all liver sections in the neonatal group were normal, so demonstrating that CAP is not an artefact of chronic biliary obstruction or liver disease.

CAP was seen in one fetus of 27 weeks' gestation demonstrating that it develops in utero, possibly at an early age stage, but more studies will be required to confirm this observation. The biochemical composition of CAP, which is located in lysosomes, ${ }^{18}$ is not established. It is unlikely to be caeruloplasmin, which has been localised to the endoplasmic reticulum, ${ }^{19}$ but may be similar to a copper-rich form of metallothionein isolated from lysosomes of normal newborn bovine liver. ${ }^{20}$

The study of copper and CAP in the neonatal and childhood groups revealed additional evidence of an association. The changes in hepatic concentration were associated with similar changes in positive orcein staining. Thus CAP was seen in the neonatal group with physiologically raised liver copper levels and was absent in the childhood control group and 15 of 16 children with liver disease and normal hepatic copper concentrations. CAP was found in 12 children with IHCC and raised hepatic copper concentrations, but was not seen in two patients with IHCC and normal hepatic copper concentrations. The appearance of CAP in cases of IHCC with raised hepatic copper concentration might suggest that copper has induced the appearance of a normal copper protein (CAP) (similar effects have been noted experimentally). ${ }^{21}$ Similar sequence of events may occur in primary biliary cirrhosis. It is possible that the amount of induced protein is proportional to the copper concentration. Supporting this suggestion is the trend of increasing hepatic copper levels to be associated with increasing grades of CAP staining in these groups.

Hepatic copper concentrations in Wilson's disease were similar to IHCC and neonates, but positive histochemical staining for copper was infrequent, suggesting that the distribution of copper accumulation in Wilson's disease may be different. This observation is similar to previous studies. ${ }^{\mathbf{2 2 2} 23}$ Also, positive staining for CAP in Wilson's disease was infrequent. In contradistinction with neonates and other forms of childhood liver disease a relationship between CAP and measured hepatic copper content was not found in Wilson's disease. From data obtained in fetuses, neonates, and children it might be expected that CAP would be present in Wilson's disease when hepatic copper levels were raised, particularly when the concentration exceeded $4 \mu \mathrm{mol} / \mathrm{g}$. However, CAP was usually absent in Wilson's disease, even when the hepatic copper concentration was as high as $28.94 \mu \mathrm{mol} / \mathrm{g}$. CAP was more commonly associated with cirrhosis in Wilson's disease. There may be several possible explanations: (1) there is a sampling error in liver biopsies. (2) Wilson's disease is a pleomorphic disorder and the appearance of CAP may represent a subgroup. Possible support for this suggestion may be the observation that each sibship of the four families revealed similar staining patterns for CAP despite wide variations in hepatic copper concentration, treatment with d-penicillamine or histological appearances. (3) Alternatively, appearance of CAP in Wilson's disease may be delayed until cirrhosis develops despite raised hepatic copper levels. Cirrhosis per se is not responsible as CAP occurred infrequently in children with cirrhosis of other aetiologies.

Hepatic copper concentrations are increased in fetuses, neonates, ${ }^{6}$ IHCC, ${ }^{24} 25$ and PBC. ${ }^{1415}$ The 
reason for the physiological increase of hepatic copper concentration in fetuses and neonates is unknown, while in IHCC and PBC it is probably secondary to chronic cholestasis. The increased hepatic copper levels in fetuses and noenates appear to be non-toxic. The hepatotoxicity of copper is not established in IHCC. ${ }^{26}$ Liver cells are normal in fetuses and neonates and raised hepatic copper levels are associated with CAP. In IHCC increased hepatic copper concentrations are always associated with CAP, a normal copper associated protein which is diffusely distributed through hepatic parenchyma. The primary disturbance of copper metabolism in the liver cells of Wilson's disease leads to increased hepatic copper concentrations, usually exceeding $4 \mu \mathrm{mol} / \mathrm{g}$ and liver damage. CAP was usually absent in Wilson's disease even when hepatic copper levels exceeded $4 \mu \mathrm{mol} / \mathrm{g}$. Thus an absence or relative deficiency of CAP may contribute to the hepatotoxic effects of copper in Wilson's disease.

This study suggests that CAP represents a physiological copper associated protein which is present in normal hepatocytes (fetuses and neonates) and reappears in response to raised concentrations of copper, which may occur with chronic cholestasis thus minimising the toxic effects of an increased copper concentration within the hepatocyte. This response is impaired in liver cells of Wilson's disease and may explain the hepatotoxic effects of copper in this condition.

J Evans is supported by a Wellcome Research Fellowship. Professor P J Scheuer reported histological specimens and contributed suggestions to the manuscript. Miss B Archer kindly performed the rhodanine and orcein histochemical stains. Dr C F Ross provided necropsy tissue of one child with intrahepatic cholestasis of childhood. Professor A E Claireaux provided hepatic tissue obtained at necropsy of the six infants in the neonatal group.

\section{References}

${ }^{1}$ Sipponen P, Salaspuro MP, Makkonen HM. Orcein positive hepatocellular material in histological diagnosis of primary biliary cirrhosis. Ann Clin Res 1975; 7: 273-7.

${ }^{2}$ Shikata T, Uzawa T, Yoshiwara N, Akasuka T, Yamazaki S. Staining methods of Australia antigen in paraffin section. Detection of cytoplasmic inclusion bodies. Jap J Exp Med 1974; 44: 25-36.

${ }^{3}$ Sipponen P. Orcein positive hepatocellular material in longstanding biliary diseases. 1 . Histological characteristics. Scand J Gastroenterol 1976; 11: 545-52.

${ }^{4}$ Salaspuro M, Sipponen P. Demonstration of an intra- cellular copper-binding protein by orcein staining in long-standing cholestatic liver disease. Gut 1976; 17: 787-90.

${ }^{5} J a i n$ S, Scheuer PJ, Archer B, Newman SP, Sherlock S. Histological demonstration of copper and copper associated protein in chronic liver disease. J Clin Pathol 1978; 31 : 784-90.

${ }^{6}$ Bruckman G, Zondek SG. Iron copper, and manganese in human organs at various ages. Biochem $J$ 1939; 33: $1845-57$.

${ }^{7}$ Sass-Kortsak A. Copper metabolism. Adv Clin Chem 1965; 8: 1-7.

${ }^{8}$ Cummings JN. Copper and iron content of brain and liver in normal and in hepato-lenticular degeneration. Brain 1948; 71: 410-5.

${ }^{9}$ Heathcote J, Deodhar KP, Scheuer PJ, Sherlock S. Intrahepatic cholestasis of childhood. $N$ Engl $J$ Med 1976; 295: 801-5.

${ }^{10}$ Alagille D, Odievre M, Gautier M, Dommergues JP. Hepatic ductular hypoplasia associated with characteristic facies, vertebral malformation, retarded physical, mental and sexual development, and cardiac murmur. J Paediatr 1975; 86: 63-71.

${ }^{11}$ Clayton RJ, Iber FL, Ruebner BH, McKusick VA. Byler's disease: fatal familial intrahepatic cholestasis in an Amish kindred. $J$ Paediatr 1965; 67: 1025-8.

${ }^{12}$ Watson GH, Miller V. Arteriohepatic dysplasia. Familial pulmonary arterial stenosis with neonatal liver disease. Arch Dis Child 1973; 48: 459-66.

${ }^{13}$ Lindquist RR. Studies on the pathogenesis of hepatolenticular degeneration. II Cytochemical methods for the localization of copper. Arch Pathol 1969; 87: 370-9.

${ }^{14}$ Smallwood RA, Williams HA. Rosenoer VM, Sherlock S. Liver copper levels in liver disease. Studies using neutron activation analysis. Lancet 1968; 2: 1310-3.

${ }^{15}$ Fleming CR, Dickson ER, Baggenstoss AH, McCall JT. Copper and primary biliary cirrhosis. Gastroenterology 1974; 67: 1182-7.

${ }^{16}$ Todd AP, Thorpe MEC, Rosenoer VM. Tissue copper determination by neutron activation analysis. $J$ Clin Pathol 1967; 20: 276-9.

${ }^{17}$ Smith $\mathrm{H}$. The distribution of antimony, arsenic, copper and zinc in human tissue. J Forensic Sci 1967; 7: 97-102.

${ }^{18}$ Sipponen $\mathrm{P}$. Orcein positive heaptocellular material in long standing biliary diseases. II. Ultrastructural characteristics. Scand J Gasterenterol 1976; 11: 545-52.

${ }^{19}$ Shaposhnikov AM, Zubzitski YN, Shulman VS. Identification of caeruloplasmin in human liver cells by fluorescent antibodies and absence of this protein in Wilson's disease. Experentia 1969; 25: 424-6.

${ }^{20}$ Porter $\mathrm{H}$. The particulate half cystine rich copper protein of newborn liver. Relationship to metallothionein and subcellular localisation in non-mitochondrial particles possibly representing heavy lysosomes. Biochem Biophys Res Commun 1974; 56: 661-8.

${ }^{21}$ Evans JE, Broadbent J. A possible experimental model for copper associated protein. Clin Sci Mol Med 1979; 57: 90 .

${ }^{22}$ Goldfischer S, Sternlieb I. Changes in the distribution of hepatic copper in relation to the progression of Wilson's disease (hepatolenticular degeneration). Am J Pathol 1968; 53: 883-901. 
${ }^{23}$ Dastur DK, Manghani DK. The liver in Wilson's disease. Some histochemical and histological aspects. Ind J Pathol Bacteriol 1967; 10: 177-83.

${ }^{24}$ Sternlieb I, Harris RC, Scheinberg IH. Le cuivre dans la cirrhose biliare de l'enfant. Rev Int Hepatol 1966; 16: 1105-10.
${ }^{25}$ Evans J, Newman S, Sherlock S. Liver copper levels in intrahepatic cholestasis of childhood. Gastroenterology 1978, 75: 875--8.

${ }^{26}$ Evans JE, Boss M, Nuttall L, Sherlock S, Zerpa H. Copper chelation therapy (penicillamine) in intrahepatic cholestasis of childhood. Gut 1979, 20 : A907. 